IOSR Journal of Pharmacy

ISSN: 2250-3013, www.iosrphr.org

Volume 2 Issue 5 \|ा| Sep-Oct. 2012 |ㅔ PP.53-56

\title{
An unusual supernuemerary third head of biceps brachii muscle in malayasian male cadaver- a case report.
}

\author{
${ }^{1}$ Ashiq, ${ }^{2}$ N.Sathyanarayana,${ }^{3}$ Chandralekha, ${ }^{4}$ Arulmoli, \\ ${ }^{1,2}$ Lecturer, Faculty of Medicine (Anatomy), AIMST University Bedong, Malayasia \\ ${ }^{3}$ Associate Professor, Department of Anatomy AIMST University, Bedong, Malaysia \\ ${ }^{4}$ Professor \&HOD Department of Anatomy AIMST University, Bedong, Malaysia
}

\begin{abstract}
Biceps brachii muscle supernumerary head have been studied regarding their origin, insertion, size, innervations, and racial differences. The most common variation is its supernumerary head. During routine dissection in the department of anatomy. we dissected Malaysian male cadaver, the variation of unusual third supernumerary head were found in the left upper arm, apart from medial bicipital aponeurosis, lateral bicipital aponeurosis was also seen. This unusual third supernumerary head innervated with musculocutaneous nerve. Review of the medical literature shows that the occurrence of infrolateral supernumerary third head of Biceps brachii muscle is no where in Malaysians. Knowledge of occurrence of infrolateral supernumerary third head of Biceps brachii muscle may become significant for the clinicians for selective motor nerve blocks, to treat the nerve impairments and for the surgeons performing arm surgeries.
\end{abstract}

Keywords-Biceps brachii, supernumerary third head, Medial bicipital aponeurosis, Lateral bicepital aponeurosis, Musculo cutaneous nerve.

\section{INTRODUCTION}

Biceps brachii is in terms of number and morphology most variable muscle in the human body. The biceps brachii is classically described as two headed muscle, long head originate from the supra glenoid tubercle and a short head from the coracoid process of scapula.

The two tendon leads in to elongated fleshy bellies uniting just distal to the middle of the arm, end in a flattened tendon, which is attached to the rough posterior area of the radial tuberosity.

The tendon has a broad triangular membranous medial expansion the bicipital aponeurosis across the cubital fossa and merges with the ante brachial deep fascia over the origin of flexor muscle in the medial side of the fore arm. ${ }^{1}$

Although the biceps is located in the anterior compartment of the arm it has no attachment to the humerus .The biceps brachi is a three joint muscle crossing and capable of effecting movement at the glenohumaral, elbow ,and superior radio -ulnar joints, even though it primarily act at the latter two. ${ }^{2}$

\section{CASE REPORT}

During routine dissection of formalin fixed an adult approximately 35 years old $250 \mathrm{~kg}$ Malaysian male cadaver in the department of anatomy at AIMST University Malaysia, the Variations were found in the anterior compartment of the left upper arm.The left biceps brachii muscle, showing the supernumerary third head infrolaterally. The supernumerary third head originated from the middle of lateral border of the anterolateral surface of humorous along the line of anterior border of the ' $\mathrm{V}$ ' shaped deltoid tuberosity. Its origin medially surrounded by the musculocutanious nerve.

The third head joining distally with the rest of the muscle and had a common insertion with flattened tendon, which is inserted to the rough posterior area of the radial tuberosity. Apart from the common insertion of the flattened tendon, a broad triangular membranous medial expansion the bicipital aponeurosis. Through another broad lateral bicipital aponeurosis has been seen over the origin of the common extensor muscle of the fore arm to the ante brachial fascia of fore arm. (Fig: 1)

This supernumerary third head of biceps brachii is supplied by a branch of musculocutanious nerve. (Fig:2) The dissection procedure was as per the Cunningham's manual. Variation were photographed and documented. 


\section{DISCUSSION}

The supernumerary third head of Biceps Brachii muscle variation explained in the light of embryogenic development. During the fifth week of development, the mesoderm invades the upper limb bud to further condense in to ventral and dorsal muscle masses. The biceps and triceps musculature is derived from the dorsal and ventral muscle masses of the upper limb buds respectively; it would be during this period of development that accessory muscle may have formed. ${ }^{3}$

Recently Rodriguez-Niedenfuhr (2003) observed 350 arms, classified the supernumerary bicipital heads based on their origin and location. Taking into account all studies and cases reported previously, they defined three different types of supernumerary bicipital heads i.e. superior, inferomedial and inferolateral humeral heads. They observed the presence of a third head in 27 out of $350(7.7 \%)$ arms. The infero-medial humeral head was observed in 31 out of $350(9 \%)$ arms and was therefore the most common variation. The superior humeral head was observed in five arms $(1.5 \%)$. The infero-lateral humeral head was the least common variation observed in 1 out of 350 arms $(0.3 \%){ }^{4}$

In the present case, the supernumerary head purely infero-lateral type, Which is similar to the observation of Rodriguez-Niedenfuhr and the third head provided approximately more than $25 \%$ of the total mass of the Biceps brachii muscle. Till today there was no such reporting regarding the presence of infrolateral unilateral supernumerary third head in Malaysian population. Hence our reporting has very significance.

Previously many authors described about the supernumerary bicepital heads ranging from 3\% to $7 \%$, among them the three headed Biceps brachii represents the most common type of variant, that has been reported ranging from $7.5 \%$ to $18.3 \% .^{5,6,7}$

Earlier workers studied racial differences in different races, among them the supernumerary third head of Biceps brachii is found in about $20.5 \%$ south African blacks, $8.3 \%$ of South African whites, $12 \%$ of black Africans, $9 \%$ Brazilian blacks, $20 \%$ of Brazilian white, $8 \%$ of Chinese, $37.5 \%$ of Colombians, $10 \%$ of white Europeans, $18 \%$ of Japanese, $2 \%$ Indian population and $15 \%$ of Turkish.,

As far as the side preference for the third head of the Biceps brachii is concerned Sweiterand Carmichael emphasized that the incidence of such head is more on the right side, but in our observation it is on left side. ${ }^{10}$ Literature review shows the incidence of its occurrence is more in males than females. But Kosogi et al and Asvat et al stated that there are no clear gender and racial differences in the occurrence of supernumerary head of biceps. ${ }^{11}$

Asvart et al observed that the third head of Biceps brachii originated from the humeral shaft either inferior to in common with the insertion area for the corachobrachialis or in common with the Brachialis muscles. The relevance of these observations in the clinical scenario is related to some physiopathological consideration. Presence of such muscular variations should be kept in mind by Surgeons and Traumatlogists. Biceps brachii will be useful as a component of flap surgery; in such cases the knowledge of the innervations of accessory head is important for plastic surgeons. ${ }^{7}$

In the present case the course and branching of musculocutanious nerve was normal. The knowledge about the supernumerary head and its nerve supply is important for clinicians for selective motor nerve blocks and to treat the nerve impairments, the surgeon should be aware of this anatomical variation during the surgical procedures. $^{12}$

\section{REFERENCES}

[1]. Williams PL, Bannister LH, Berry MM.et al .In Grays's anatomy: The anatomical basis of medicine and surgery $.40^{\text {th }}$ ed. Edinburgh, ELBS Churchill Livingstone 1995; PP 843.

[2]. Keith-L-Moore, Arther-F-Dally. Clinically oriented anatomy $.5^{\text {th }}$ Edition 2006 page 785

[3]. Nayak SR, Krishnamurthy A, Kumar M et al. Four headed Biceps and Triceps brachi muscle, with neurovascular variation Anat.Sci.Lut:2008; 83:107.11

[4]. Rodriguez- Niedenfuhr M, Vazquez T, Choi D, Parkin I, Sanudo JR. Supernumerary humeral heads of the Biceps brachii muscle revisited. Clin Anat. 2003; 16: 197-203

[5]. Abu-Hijleh M.F. Three headed Biceps Brachii muscle associated with duplicated musculocutanious nerve Clin Ant 2005.18:376-9

[6]. Neto H.S Camith, JA Andrade. On the incidence of the Biceps brachii third head in Brazilian whites and blacks Ann Anta 1998; 180.69-71

[7]. Asvat R, Candler P, Sarmiento EE. High incidence of third head of Biceps brachii in South African population. J Anat 1993; 182: 101-104.

[8]. Bergman RA,Thompson SA, Afifi AK. Compendium of Human Anatomic Variations. Baltimore: Urban \& Schwarzenberg, 1988; 139-143.

[9]. Tountas CP, Bergman RA. Anatomic variation of the upper extremity.NewYork:Churchill Living stone 1993;97-9

[10]. SweiterM.C, CarmichaelS.W. Bilateral three headed Biceps brachii muscle Anat.Anz 980:148:346-49 . 
[11]. 11. Kosugi K, Shibata S, Yamashita H. Supernumerary head of Biceps brachii and braching pattern of musculocutaneous nerve in Japanese. Surg Radiol Anat 1992; 4:175-85

[12]. Rai R Ranade AV, Prabhu LV, Pai MM, Prakash. Third head of Biceps brachii in an Indian population. Singapore Med J 2007; 48: 929-931

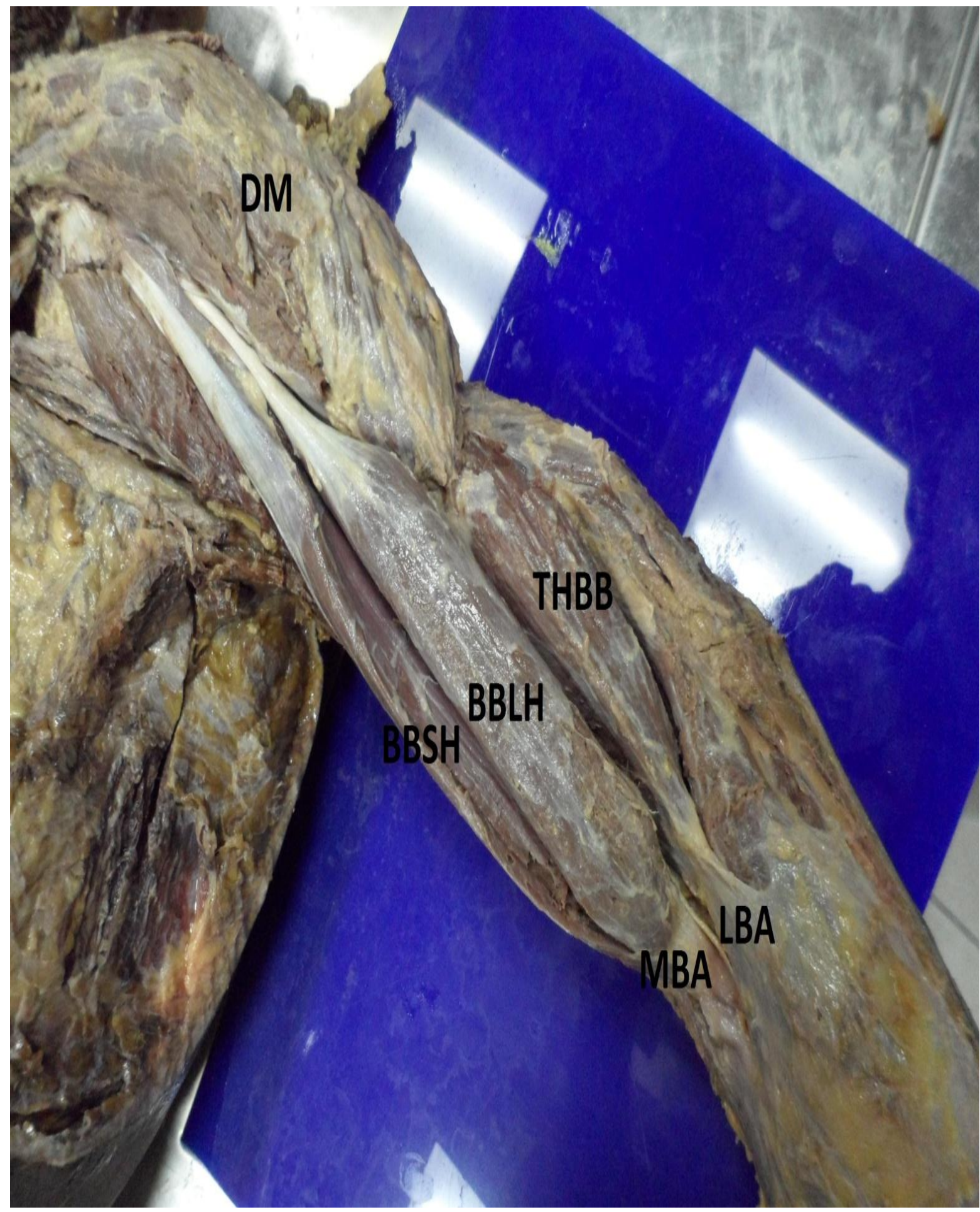

Fig.1 Showing the variation of the biceps brachii muscle. Infrolateral Supernuemerary head of Biceps brachii muscle

$\mathrm{DM}=$ Deltoid Muscle, $\mathrm{BBSH}=$ Biceps Brachi Short Head,BBLH = Biceps Brachii Long Head

THBB = Third Head of Biceps Brachi ,LBAN= Lateral bicepital apponurosis ,

MBA=Medial Bicepital Apponurosis 


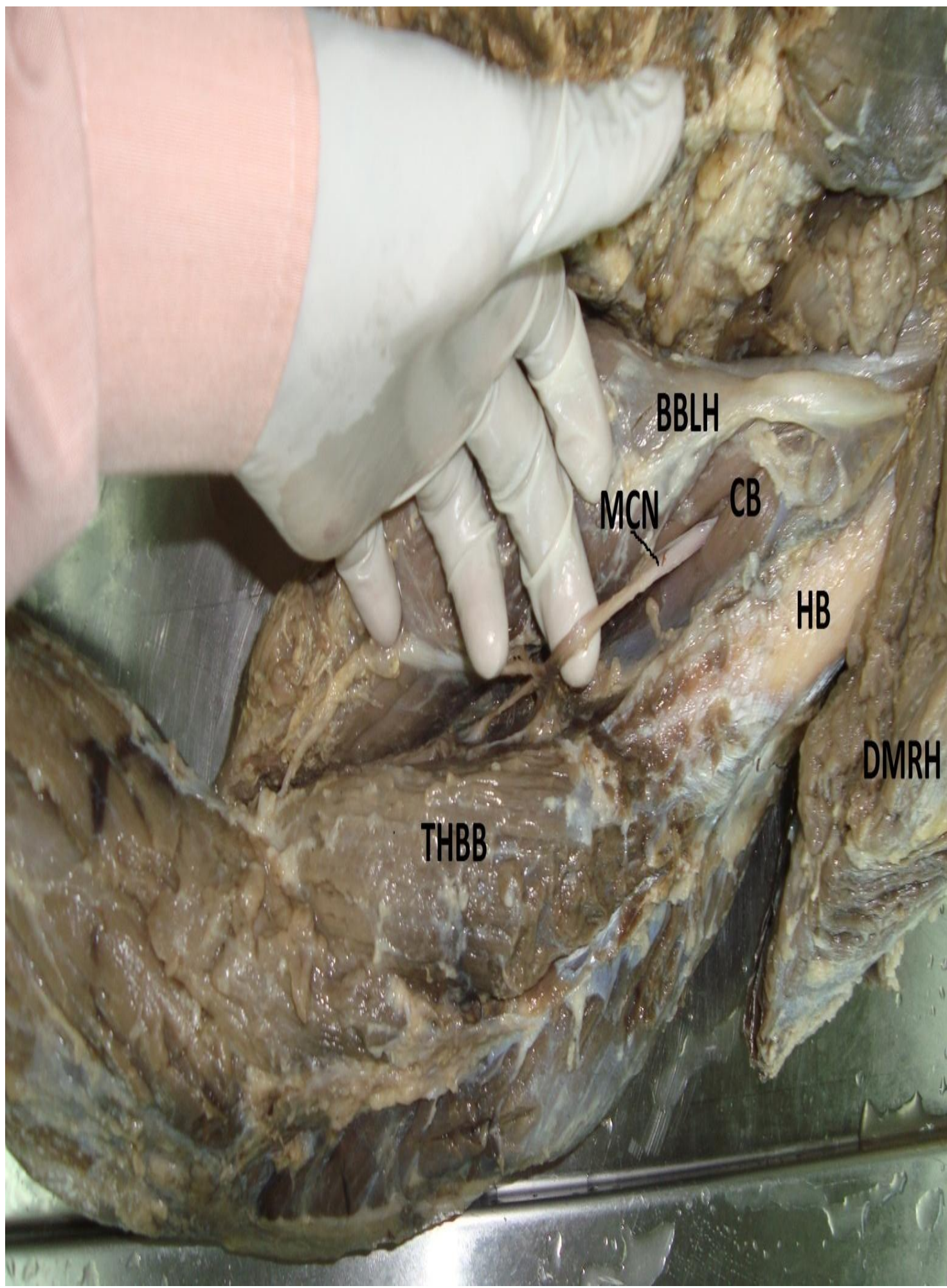

Fig: 2 showing third head of Biceps Brachii supplied by Musculocutaneous nerve. $\mathrm{DM}=$ Deltoid Muscle, $\mathrm{BBSH}=$ Biceps Brachii Short Head, BBLH = Biceps Brachii Long Head THB $=$ Third Head of Biceps Brachii, LBAN= Lateral bicepital apponurosis 